\title{
Editorial
}

\section{Enhancing nuclear and radiological emergency management and rehabilitation: Key results of the EURANOS European project}

\section{Background}

When setting up the concept and the content of the EURANOS (European Approach to Nuclear and Radiological Emergency Management and Rehabilitation Strategies) project in 2003/2004, it was obvious, that in the past 17 years since the Chernobyl accident, considerable resources have been devoted in Europe and elsewhere to improve the management of off-site consequences of nuclear emergencies and the rehabilitation of contaminated territories. Significant progress has been achieved in the information technological (IT) and methodological areas of emergency management and response through national initiatives and with support of the EC under its 4th and 5th Framework Programmes (FP4 and FP5). Many RTD (Reasearch and Technological Development) tools were available for operational use by those with responsibility for emergency management and their application in practice. Prominent examples were the installation of gamma monitoring systems in Eastern and Western European countries, the collection and evaluation of their data under EURDEP (EUropean Radiological Data Exchange Platform), the further development and installation of the decision support systems ARGOS and RODOS in many Eastern and Western European countries, and the development of tools and methods for exchanging data and information between neighbouring countries.

As far as the long term rehabilitation of contaminated rural, urban or industrial areas is concerned the situation was less advanced. Most efforts during FP4 and FP5 were devoted to comprehensive analysis and evaluation of countermeasures using the extensive experience in the contaminated territories of the FSU (Former Soviet Union). Although not yet complete, this work constituted a common European basis for any further developments concerning both the decision support systems for planning the long term management of affected territories and the rehabilitation strategies to be implemented at the local, regional and national levels of affected areas. Beyond these developments, the issues raised by the long term rehabilitation of living conditions for the population in contaminated territories had not received much attention and many questions remained unresolved. The only original experience resulted from the ETHOS project that took place from 1996 to 2001 in the contaminated territories of Belarus with the support of the European Commission. This project demonstrated that, in addition to the top-down approach that was implemented during the early, late and long-term rehabilitation phases, a decentralised approach, relying on the involvement of all affected stakeholders is

DOI: $10.1051 /$ radiopro/2010034 
EDITORIAL

not only possible but necessary, to improve the quality of the whole rehabilitation process.

Beyond the maintenance of the present state of knowledge and competence achieved through training, the main aim of the EURANOS project was to improve the coherence and the effectiveness of the methods, strategies, guidance and tools developed so far and to demonstrate their operational use. A further objective was to favour the progressive building of a common emergency management and rehabilitation culture in Europe. Emergency management and response as well as rehabilitation strategies, in the case of a radiological accident in Europe was still characterised by largely national solutions in both technical and administrative/political areas. Furthermore, infrastructures and technical solutions for monitoring, decision support and information exchange still showed a large variation in equipment and software between Member States. The level of involvement of relevant members of society and the availability of information of the general population was also very different from one country to another.

To overcome these deficiencies and to increase the efficacy and coherence in nuclear and radiological emergency management and rehabilitation response in Europe, the following issues needed to be tackled within EURANOS:

- any nuclear accident in Europe has a cross-border dimension, which forces neighbouring countries to closely interact by using consistent and widely accepted procedures, methods and techniques;

- given present and likely future resource constraints, there is a necessity to make better use of the European effort for collective benefit;

- there is a need to take steps for better maintaining knowledge and competence through more integrated and joint actions, in particular, as accidents occur very rarely;

- recently developed RTD methods, tools, procedures and guidance have not yet been fully exploited and an increased effort is needed to promote their better take up through demonstration projects;

- additional RTD is needed in a few critical areas, and - in particular - in solving the longer term problems following an emergency such as the restoration of the affected territories and rehabilitation of living conditions for those groups of the population who have decided to reside in these areas.

\section{Realisation}

The European dimension of the project could only be achieved with a sufficiently large number of partners. Furthermore, having identified the end users in the operational emergency management centres as one important target audience of the project, a mix of partners from research and the operational community was 
EDITORIAL

essential. This has been realised with 50 partners from 23 European countries combining 33 research organisations with 17 national emergency management centres. The five year project ran from 2004-2009.

The project was structured according to the areas that were identified as most requiring development, i.e.

- demonstration activities (end users perspective);

- research activities with three major categories of work;

- CAT1: all activities related to emergency actions and countermeasures;

- CAT2: all activities related to the further enhancement of decision support systems for operational application;

- CAT3: all activities related to rehabilitation strategies and guidance.

- training and dissemination;

- management (through a Management Committee).

The continual input and feedback from the end user community was an essential component of the project. Consequently, about $20 \%$ of the total budget was not initially allocated. This allowed the Management Committee to be flexible to respond to the end users' recommendations and to restructure the work program accordingly. Prominent result of this flexibility was the re-engineering of the RODOS system based on demands of the operational centres.

\section{Structure of the special issue}

The objective of this special issue is to present the major achievements of the EURANOS project. Therefore, the structure follows the major work packages identified when setting up the project. This results in sections dealing with

- handbooks (2 papers);

- modelling (10 papers);

- improvement of Decision Support systems (5 papers);

- long term rehabilitation (3 papers);

- demonstrations ( 3 papers).

Starting with this editorial, the first paper presents an overview, summarising the main achievements of EURANOS. In the Handbook section, the first paper describes in detail the set of compendia and handbooks developed for food production systems, inhabited areas and drinking water resources. The second paper here provides strategies related to the lifting of early emergency countermeasures. This comprises a European wide review on procedures and recommendations when to and how to lift early phase countermeasures, an area that is often not considered adequately in national regulations. 
EDITORIAL

The modelling sections starts with an overview about the major achievements in the simulation models either newly developed or improved. Papers about ERMIN and AgriCP describe the new countermeasure simulation models for inhabited areas and food production systems, respectively. Both contain new features that make them unique in Europe. Four papers deal with atmospheric transport and dispersion modelling. One of them describes the new particle model DIPCOT that allows the application of RODOS also in highly structured terrain. A further one presents the improvements made for the long range dispersion model Match. The other two papers present comparison and validation exercises performed with the three dispersion models of RODOS and a comparison exercise between locally monitored weather data and predicted data. The latter demonstrated that there is always a difference between local and predicted data that is important with respect to the wind direction. This information is extremely important for selecting areas of countermeasures. The new hydrological model chain is described in one paper followed by achievements realised in the area of data assimilation and evaluation strategies; the latter paper demonstrates its importance in the later phase of an emergency.

The section dealing with general improvements of decision support systems focused on the operability aspects of ARGOS and RODOS: in particular guidance for data assimilation features; the application of EURANOS simulation modules in the ARGOS system, the newly developed user friendly input interface of RODOS and finally the re-engineered RODOS system. All these papers demonstrate the importance of the end users' perspective that was continuously monitored by the EURANOS Management Committee and implemented in those activities.

The long term rehabilitation section describes the basics of the new European Framework for post-accident rehabilitation preparedness, its implementation in France and Norway and the experience gained with the application of EURANOS products - here the RODOS system - at the local level for investigations on rehabilitation preparedness in particular, as well as preparedness for all phases of an emergency.

The final section of this special issue deals with the demonstration projects that were carried out in the EURANOS project. There is a summary paper describing the main demonstrations and individual papers relating to the demonstration of the handbooks and the MOIRA system. These two papers describe in more detail the planning, performance and evaluation of a demonstration project.

\section{Acknowledgement}

The editors would like to thank the representatives of the European Commission supervising the EURANOS project for their continuous support and engagement. 
EDITORIAL

We also would like to thank the members of the Management Committee namely:

- Joachim Ehrhardt (coordinator for the first year of the project);

- Florian Gering;

- Jacques Lochard;

- Mary Morrey (moved after a year to the Advisory Committee);

- Anne Nisbet;

- Wolfgang Raskob;

- Vera Starostova;

- Bojan Tomic.

for their commitment to the project and their never ending attempts to find optimal solutions for the sake of the project.

The editors would like to thank the members of the Advisory Committee providing advice not only to issues of the project but to important aspects of emergency management and rehabilitation in general:

- Hannele Aaltonen;

- G. Neale Kelly;

- Ted Lazo;

- Mary Morrey (partly);

- André Oudiz;

- Carlos Rojas-Palma

- Vesa Tanner

- Wolfgang Weiss

The editors would like to thank in particular all those participated in the project from the following organisations:

\begin{tabular}{|c|c|c|}
\hline Participants name & Short name & Country \\
\hline $\begin{array}{l}\text { Karlsruhe Institute of Technology (former Forschungszentrum } \\
\text { Karlsruhe } \mathrm{GmbH} \text { ) }\end{array}$ & KIT (FZK) & Germany \\
\hline Belgian Nuclear Research Centre & $\mathrm{SCK} \cdot \mathrm{CEN}$ & Belgium \\
\hline $\begin{array}{l}\text { Centre d'étude sur l'évaluation de la protection dans le } \\
\text { domaine nucléaire }\end{array}$ & CEPN & France \\
\hline $\begin{array}{l}\text { Health Protection Agency (before April 2005: National } \\
\text { Radiological Protection Board) }\end{array}$ & HPA (NRPB) & United Kingdom \\
\hline Enconet Consulting Ges.m.b.H. & ENCONET & Austria \\
\hline GSF-Forschungszentrum für Umwelt und Gesundheit GmbH & GSF & Germany \\
\hline Radiation and Nuclear Safety Authority & STUK & Finland \\
\hline VUJE Trnava a.s. & VUJE & Slovak Republic \\
\hline Nuclear Regulatory Authority of the Slovak Republic & UJD & Slovak Republic \\
\hline Gesellschaft für Anlagen- und Reaktorsicherheit (GRS) m.b.H. & GRS & Germany \\
\hline
\end{tabular}


EDITORIAL

\begin{tabular}{|c|c|c|}
\hline Participants name & Short name & Country \\
\hline National Nuclear Corporation Limited & $\mathrm{NNC}$ & United Kingdom \\
\hline $\begin{array}{l}\text { European Commission - Directorate General Joint Research } \\
\text { Centre }\end{array}$ & EC-DG JRC & Italy \\
\hline RISOE National Laboratory & RISO & Denmark \\
\hline Bundesamt für Strahlenschutz & BfS & Germany \\
\hline $\begin{array}{l}\text { Niedersächsicher Landesbetrieb für Wasserwirtschaft, Küsten } \\
\text { und Naturschutz }\end{array}$ & NLWKN & Germany \\
\hline National Centre for Scientific Research DEMOKRITOS & NCSRD & Greece \\
\hline Danish Emergency Management Agency & DEMA & Denmark \\
\hline Prolog Development Center A/S & PDC & Denmark \\
\hline ENVIROWARE srl & Envware & Italy \\
\hline Aristotle University of Thessaloniki & AUTH & Greece \\
\hline The University of Ioannina & UOI & Greece \\
\hline Universität Karlsruhe (TH) & UniKarl & Germany \\
\hline Institut de radioprotection et de surété nucléaire & IRSN & France \\
\hline Natural Environment Research Council & $\mathrm{CEH}$ & United Kingdom \\
\hline Nuclear Research and Consultancy Group & NRG & The Netherlands \\
\hline Institut national agronomique Paris-Grignon & INAPG & France \\
\hline Norges Landbrukshogskole & $\mathrm{NLH}$ & Norway \\
\hline Statens stralevern & NRPA & Norway \\
\hline $\begin{array}{l}\text { Austrian Federal Ministry of Agriculture, Forestry, } \\
\text { Environment and Water Management }\end{array}$ & BMLFUW & Austria \\
\hline Division de la Radioprotection - Ministère de la Santé & MSLux & Luxemburg \\
\hline Rijksinstituut voor Volksgezondheid en Milieu & RIVM & The Netherlands \\
\hline Instituto do Ambiente & IA & Portugal \\
\hline Consejo de Seguridad Nuclear & CSN & Spain \\
\hline Nuclear Research Institute Rez plc & UJV Rez & Czech Republic \\
\hline Scientific Production Association TYPHOON & SPA TYPHOON & Russia \\
\hline Kungliga Tekniska Högskolan & KTH & Sweden \\
\hline Slovenian Nuclear Safety Administration & SNSA & Slovenia \\
\hline Universidad Politécnica de Madrid & UPM & Spain \\
\hline $\begin{array}{l}\text { Centro de Investigaciones Energeticas Medioambientales y } \\
\text { Tecnologicas }\end{array}$ & CIEMAT & Spain \\
\hline Institute of Atomic Energy & IAE & Poland \\
\hline National Atomic Energy Agency & NAEA & Poland \\
\hline
\end{tabular}


EDITORIAL

\begin{tabular}{lll}
\hline Participants name & Short name & Country \\
\hline VEIKI - Institute for Electric Power Research Co. & VEIKI & Hungary \\
\hline ENEA - Ente per le Nuove tecnologie l'Energia e l'Ambiente & ENEA & Italy \\
\hline Studsvik RadWaste AB & STUDSVIK & Sweden \\
\hline Mutadis Consultants & MUTADIS & France \\
\hline $\begin{array}{l}\text { State Office for Nuclear Safety } \\
\text { Ministry of the Interior - National Directorate for Disaster } \\
\text { Management }\end{array}$ & SUJB & Czech Republic \\
\hline $\begin{array}{l}\text { Sveriges Meteorologiska och Hydrologiska Institut } \\
\begin{array}{l}\text { Nationale Alarmzentrale - National Emergency Operations } \\
\text { Centre }\end{array}\end{array}$ & NAHI - NEOC & Hungary \\
\hline Ukrainian Center for Environmental and Water Projects & UCEWP & Ukraine \\
$\begin{array}{l}\text { National Institute of R\&D for Physiscs and Nuclear } \\
\text { Engineering Romania }\end{array}$ & NIPNE & Romania \\
\hline
\end{tabular}

The editors would like to thank the authors for their contribution to this special issue.

This work has received partial financial support from the European Commission Sixth Framework Programme (Nuclear Fission/Radiation Protection) under the EURANOS integrated project: European approach to nuclear and radiological emergency management and rehabilitation strategies (Contract No: FI6R-CT2004-508843). 